\title{
Oxidative Stress, Cell Death, and Other Damage to Alveolar Epithelial Cells Induced by Cigarette Smoke
}

\author{
Aoshiba K, Nagai A \\ First Department of Medicine, Tokyo Women's Medical University, Tokyo, Japan
}

\begin{abstract}
Cigarette smoking is a major risk factor in the development of various lung diseases, including pulmonary emphysema, pulmonary fibrosis, and lung cancer. The mechanisms of these diseases include alterations in alveolar epithelial cells, which are essential in the maintenance of normal alveolar architecture and function. Following cigarette smoking, alterations in alveolar epithelial cells induce an increase in epithelial permeability, a decrease in surfactant production, the inappropriate production of inflammatory cytokines and growth factors, and an increased risk of lung cancer. However, the most deleterious effect of cigarette smoke on alveolar epithelial cells is cell death, i.e., either apoptosis or necrosis depending on the magnitude of cigarette smoke exposure. Cell death induced by cigarette smoke exposure can largely be accounted for by an enhancement in oxidative stress. In fact, cigarette smoke contains and generates many reactive oxygen species that damage alveolar epithelial cells. Whether apoptosis and/or necrosis in alveolar epithelial cells is enhanced in healthy cigarette smokers is presently unclear. However, recent evidence indicates that the apoptosis of alveolar epithelial cells and alveolar endothelial cells is involved in the pathogenesis of pulmonary emphysema, an important cigarette smoke-induced lung disease characterized by the loss of alveolar structures. This review will discuss oxidative stress, cell death, and other damage to alveolar epithelial cells induced by cigarette smoke.
\end{abstract}

KEY WORDS: Cigarette smoking, oxidants, necrosis, pulmonary emphysema

\section{INTRODUCTION}

Cigarette smoking is a major risk factor in the development of lung diseases including, pulmonary emphysema, pulmonary fibrosis, and lung cancer. The mechanisms of these diseases include alterations in the alveolar epithelium, which is essential for the maintenance of normal alveolar architecture and function.

Alveolar epithelial cells are the lung's first line of defense against the external environment. These cells also produce surfactants to reduce surface tension, release cytokines to regulate inflammation, generates growth factors and matrix proteins to promote repair processes, and release proteinases and proteinase in- hibitors to regulate the turnover of alveolar matrix proteins. When injured, alveolar epithelial cells participate in repair processes by initiating recruitment, proliferation, and differentiation into new alveolar epithelial cells. Therefore, alterations in alveolar epithelial cells may cause architectural and functional disruptions in the alveolar epithelium. In this context, exposure to cigarette smoke may induce an increase in epithelial permeability, a decrease in surfactant production, the inappropriate generation of inflammatory cytokines and growth factors, and an increased risk of lung cancer. However, the most deleterious effect of cigarette smoke on alveolar epithelial cells is cell death, i.e., either apoptosis or necrosis. Cell death induced by cigarette

Correspondence: Kazutetsu Aoshiba, First Department of Medicine, Tokyo Women's Medical University, 8-1 Kawada-cho, Shinjuku-ku, Tokyo 162-8666, Japan Email: kaoshiba@chi.twmu.ac.jp Fax: 81-3-5379-5457 
smoke exposure can largely be accounted for by an enhancement in oxidative stress.

Cigarette smoke contains more than 4,000 chemicals, many of which are known to be carcinogenic and injurious [1,2]. Importantly, cigarette smoke contains and generates various reactive oxygen species (ROS) and reactive nitrogen species (RNS), such as superoxide radical, hydrogen peroxide, hydroxyl radical, and peroxynitrite. Recent evidence indicates that the ROS and RNS in cigarette smoke damage alveolar epithelial cells. In this review, we will begin with a general description of alveolar epithelial cells and thereafter discuss oxidative stress, cell death, and other damage to alveolar epithelial cells induced by cigarette smoke.

\section{ALVEOLAR EPITHELIAL CELLS}

The alveolar epithelium is composed of two different cell types, alveolar type I cells and alveolar type II cells $[3,4]$. Alveolar type I cells are terminally differentiated, large, flat cells that line more than $90 \%$ of the alveolar surface and account for $7 \%$ of parenchymal lung cells [5]. They are relatively simple cells that contain a small nucleus, a few small mitochondria, some endoplasmic reticulum cisternae with ribosomes, interspersed microfilaments, and an inconspicuous Golgi apparatus, all located in the perinuclear cytoplasm [3]. The thin and attenuated cytoplasm of type I cells facilitates gas exchange by minimizing the diffusion distance between the alveolar gas and the blood.

Alveolar type II cells are predominantly located in the corners of the alveoli. They cover about $10 \%$ of the alveolar surface and account for $15 \%$ of all parenchymal cells [5]. Alveolar type II cells are cuboidal in shape and contain many organelles, including mitochondria, endoplasmic reticulum, microfilaments, and Golgi apparatus (4). They also possess lamellar bodies, which are unique organelles that contain layers of surfactant phospholipids; surfactant proteins $\mathrm{A}, \mathrm{B}$, and C; lysosomes; and lysosomal enzymes [4]. The main function of alveolar type II cells is the synthesis and secretion of surfactant, a lipid and protein mixture involved in the reduction of surface tension in the alveoli. Alveolar type II cells are also involved in a variety of functions [4]. These functions include xenobiotic metabolism, through the activity of P450 enzymes [6]; the regulation of transepithelial ion transport [7]; the production of extracellular matrix proteins, such as fibronectin, type IV collagen, and proteogycan; and the expression of cytokines and growth factors, such as IL6, IL-8, monocyte chemotactic protein-1, TNF $\alpha$, TGF $\alpha$,
TGF $\beta$, GM-CSF, and endothelin-1 [4]. Another important function of alveolar type II cells is their participation in epithelial repair processes. Following epithelial injury, alveolar type II cells migrate to the denuded area, proliferate into new alveolar type II cells, and differentiate into alveolar type I cells $[4,8]$. In this context, alveolar type II cells are considered to be the progenitors of alveolar epithelial cells.

\section{SYSTEMIC AND LOCAL OXIDATIVE STRESS INDUCED BY CIGARETTE SMOKE EXPOSURE}

Cigarette smoke has been calculated to contain $10^{17}$ oxidant molecules/puff, of which $10^{14}$ are ROS [1]. The gas phase of cigarette smoke mainly contains shortlived ROS, such as superoxide radical and nitrogen oxide, both of which immediately react to form highly reactive peroxynitrite. In contrast, the tar phase contains the long lived hydroquinones that undergo redox-cycle to form superoxide radical and hydrogen peroxide via semiquinones, thereby resulting in persistent oxidative stress $[2,9,10]$. Hydroquinones and hydrogen peroxide can enter cells and may even reach the nucleus, where they may cause oxidative DNA damage $[9,11]$. Some constituents of cigarette smoke may also release iron from ferritin, potentiating oxidative stress within lung cells [12]. Besides these direct mechanisms of enhanced oxidative stress, cigarette smoke also increases oxidative stress in the lungs by recruiting and activating phagocytes to release ROS [13]. Cigarette smoke also reduces extracellular and intracellular antioxidant capacity. For example, exposure to cigarette smoke decreases blood levels of antioxidants, including ascorbate, urate, ubiquinol-10, $\alpha$-tocopherol, and $\beta$-carotene $[14,15]$. Acute cigarette smoke exposure also reduces glutathione levels with decreases in glutathione peroxidase and glucose- 6 phosphate dehydrogenase activities in alveolar type II cells, erythrocytes, and lung epithelial lining fluids [16-20]. In contrast, chronic cigarette smoke exposure elevates glutathione levels with increases in those activities [19,21-23]. However, these adaptive increases in antioxidant levels may not be sufficient to protect the alveolar epithelial cells against oxidative stress in chronic smokers.

\section{OXIDATIVE DAMAGE IN ALVEOLAR EPITHELIAL CELLS FROM CIGARETTE SMOKE EXPOSURE}

Cigarette smoke causes oxidative damage in alveolar epithelial cells. In vitro experiments with freshly 
isolated alveolar type II cells or the alveolar type II cell line (A549) have shown that cigarette smoke enhances intracellular ROS levels with a depletion of glutathione, thereby causing cell growth arrest, cell detachment, cell lysis, and enhanced epithelial permeability $[18,20,24]$. Importantly, cigarette smoke is also capable of activating alveolar and bronchial epithelial cells to elicit inflammatory responses. For example, volatile components of cigarette smoke, presumably acetaldehyde and acrolein, stimulate the release of IL-8 through the mechanism of protein kinase $\mathrm{C}$ activation [25-28). Thus, cigarette smoke has either toxic or stimulatory effects on lung epithelial cells, probably depending on the magnitude of cigarette smoke exposure, the cell status, and the antioxidant levels of the cells.

Oxidative damage in alveolar epithelial cells by cigarette smoke includes oxidation of DNA adducts [29]. A previous study has shown that the acute exposure of mice to cigarette smoke induces oxidative DNA adduction, detected by an increase in 8-hydroxy-2'deoxyguanosine $(8-\mathrm{OHdG})$ levels in the heart, liver, and lung tissues [30]. Similarly, we have found that the immunohistochemical levels of 8-OHdG were dramatically increased in the alveolar and bronchial epithelial cells of mice one hour after cigarette smoke exposure; these levels then declined to their basal values after 16 hours [Aoshiba, unpublished observations]. Interestingly, we noted greater cellular levels of $8-\mathrm{OHdG}$ in alveolar type II cells than in alveolar type I cells, suggesting that cigarette smoke imposes greater DNA damage in alveolar type II cells [Aoshiba, unpublished observations]. Our discovery of greater sensitivity of alveolar type II cells to cigarette smoke is interesting because alveolar type II cells are thought to be somewhat resistant to other inhaled oxidants such as $\mathrm{NO}_{2}$ and ozone [31]. We speculate that the sensitivity of alveolar epithelial cells to these gaseous oxidants may be different from their sensitivity to cigarette smoke, which contains many different oxidants in both gaseous and particle (tar) components. Alternatively, alveolar type II cells are more metabolically active than alveolar type I cells, and thus the basal levels of cellular oxidants may be higher in type II cells than in type I cells. Furthermore, type II cells are located at the corners of the alveolar septa, whereas type I cells reside between the corners, and this difference in location may influence the level of cigarette smoke exposure in the microenvironment. Alveolar type II cells are considered to be the progenitor of alveolar epithelial cells, and if type II cells are damaged by oxidative stress caused by repeated smoking, that may interfere with restoration of the alveolar epithelium. This process may be related to the alveolar destruction that leads to pulmonary emphysema in cigarette smokers.

Previous studies have indicated that hydroquinone and catechol are important constituents of cigarette smoke that initiate oxidative damage to the DNA $[32,33]$. For example, autoxidation of hydroquinone and catechol has been shown to generate hydrogen peroxide, which is iron-catalyzed to form the hydroxyl radical, leading to deoxyguanosine hydroxylation, endonuclease activation, and DNA strand breaks [32-37]. The hydroxyl radical also activates poly (ADP-ribose) polymerase (PARP), a 116-kd DNA repair enzyme that synthesizes poly (ADP-ribose) polymers in response to the formation of DNA strand breaks [38]. The activation of PARP causes a decrease in cellular nicotinamide adenine dinucleotide (NAD) levels that is sufficient to interfere with ATP synthesis and to cause cell death $[39,40]$. In fact, a previous study showed that the death of alveolar epithelial cells following cigarette smoke exposure was inhibited by the PARP inhibitor 3aminobenzamide, supporting the involvement of PARP activation in cigarette smoke-mediated damage in alveolar epithelial cells [38]. In addition to ROS, reactive nitrogen species (RNS) may also contribute to the mechanism of DNA damage by cigarette smoke. For example, the exposure of bronchial epithelial cells to cigarette smoke produces xanthine and hypoxanthine, presumably resulting from the RNS-mediated deamination of guanine and adenine, respectively [41].

The exposure of lung cells to oxidative stress is generally followed by adaptive increases in the intracellular levels of many antioxidants including manganese superoxide dismutase (MnSOD), copper-zinc superoxide dismutase (CuSOD), catalase, and glutathione peroxidase (GP) [42]. Within cells, MnSOD is concentrated in the mitochondria. CuSOD and GP are mainly located in the cytoplasma and nucleus, and catalase is found predominantly in peroxisomes. The increased expression of these antioxidants protects cells from oxidative injury. An animal study has shown that rat exposed to cigarette smoke for 14 days exhibited an enhancement in the bronchial epithelial expression of antioxidant genes encoding manganese superoxide dismutase, glutathione peroxide dismutase, and metallothionein [43]. We also found that mice exposed to cigarette smoke for one hour exhibited an enhancement in the alveolar and bronchial epithelial expression of $\gamma$ glutamylcysteine synthetase ( $\gamma$-GCS), the rate-limiting enzyme that catalyzes the de novo synthesis of glutathione (unpublished observations). Our in vivo find- 
ings were supported by in vitro experiments with A549 cells, which showed a dramatic depletion of intracellular glutathione, followed by the induction of $\gamma$-GCS gene expression in association with an increase in the DNA binding of AP-1/AP-1-like elements [19,20,24,44]. The expression of antioxidants such as $\gamma$-GCS and heme oxygenase- 1 following oxidative stress is also known to be stimulated by the binding of the antioxidant response element to the $\mathrm{Nrf2}$ transcription factor (45). The adaptive synthesis of glutathione following cigarette smoke exposure may be relevant to the elevated glutathione levels in the epithelial lining fluid of cigarette smokers $[19,21,46]$.

Few studies have examined the synthesis of antioxidants by alveolar type I cells compared to alveolar type II cells because the alveolar type I cells are difficult to culture in vitro. Several in vivo studies have shown that the cellular levels of glutathione-synthesizing enzymes, such as $\gamma$-glutamyltranspeptidase and glutathione peroxidase, are greater in alveolar type II cells than in alveolar type I cells [47,48]. The greater cellular levels of the antioxidant enzymes in alveolar type II cells than in alveolar type I cells may be important, because alveolar type II cells are more metabolically active than alveolar type I cells, and thus the basal levels of cellular oxidants may be higher in alveolar type II cells than in alveolar type I cells.

\section{DEATH OF ALVEOLAR EPITHELIAL CELLS INDUCED BY CIGARETTE SMOKE EXPOSURE}

Cigarette smoke-induced oxidative damages in alveolar epithelial cells ultimately causes cell death $[20,49]$. The type of cell death, either apoptosis or necrosis, depends on the magnitude of cigarette smoke exposure. A recent study with A549 cells has shown that aqueous extracts of cigarette smoke induced apoptosis at low concentrations $(<5 \%)$ and necrosis at high concentrations $(>10 \%)$ [49]. These cytotoxic effects were largely the results of ROS and aldehydes present in the volatile phase of cigarette smoke; the effects were attenuated by the oxidant scavenger $\mathrm{N}$ acetylcysteine or the aldehyde scavenger aldehyde dehydrogenase [49]. Interestingly, the cigarette smokeinduced apoptosis of A549 cells was not associated with the activation of caspases, which agrees with our findings on the cigarette smoke-induced apoptosis of alveolar macrophages [50]. These findings can be explained by the fact that activity of caspases requires cysteine residues, which is inactivated by the ROS in cigarette smoke [51]. Another study has shown that acrolein, a major volatile constituent of cigarette smoke, also induces the apoptosis of bronchial epithelial cells by generating ROS [52]. The in vitro ability of cigarette smoke to induce apoptosis was supported by an in vivo study demonstrating that the exposure of rats to cigarette smoke for approximately 100 days induced apoptosis of bronchial epithelial cells; the bronchial epithelial cells apoptosis was prevented by the oral administration of the antioxidant $\mathrm{N}$-acetylcysteine [53]. Cigarette smoke exposure in rats has also been shown to augment asbestos-mediated DNA strand breaks and necrosis in bronchial epithelial cells [54].

The molecular mechanisms of the cigarette smoke-induced death of alveolar epithelial cells are not well understood. Recent studies have shown that hydrogen peroxide induces the apoptosis of alveolar or bronchial epithelial cells by activating a signaling pathway involving the depletion of glutathione, the activation of a $\mathrm{Mg}^{2+}$-dependent neutral sphingomyelinase, and the generation of ceramide [55-57]. However, whether cigarette smoke-induced apoptosis utilizes the same signaling pathway remains unclear because oxidative stress is capable of activating various signaling molecules, including NFKB, extracellular signalregulated kinase ERK1/ERK2, and GADD genes $[58,59]$. On the other hand, cigarette smoke exposure may cause mitochondrial dysfunction, potentially leading to apoptosis or necrosis. For example, a recent study has shown that cigarette smoke exposure in mice causes mitochondrial DNA damage and protein nitration, with a reduction in mitochondrial enzyme activities in cardiovascular tissues [60]. Since the lung is the primary target of cigarette smoke exposure, cigarette smoke may also cause mitochondrial dysfunction in alveolar epithelial cells.

\section{DEATH OF ALVEOLAR EPITHELIAL CELLS IN CIGARETTE SMOKE-INDUCED LUNG DISEASES}

Whether or not alveolar epithelial cells undergo cell death in healthy human smokers remains largely unconfirmed. However, recent evidence suggests that an enhancement in the death of alveolar epithelial cells may participate in the pathogenesis of pulmonary emphysema, an important cigarette smoke-associated lung disease characterized by the loss of alveolar cells. For example, clinical studies have recently shown elevated levels of apoptosis in epithelial and endothelial cells in the alveolar wall of smokers with pulmonary emphysema $[61,62]$. An animal study with rats has also shown 
that the chronic inhibition of the vascular endothelial growth factor receptor induced apoptosis in alveolar endothelial cells, followed by pulmonary emphysema [63]. Furthermore, we have found that alveolar epithelial transfection with active caspase- 3 causes the apoptosis of alveolar epithelial cells and the subsequent development of emphysema in mice (64). Taken together, these findings suggest that epithelial and/or endothelial apoptosis may contribute to the alveolar cell loss that characterizes pulmonary emphysema.

The loss of alveolar epithelial cells resulting from cigarette smoke exposure must be offset by the initiation of epithelial repair processes. However, cigarette smoke exposure has been shown to inhibit the ability of epithelial cells to migrate, attach to the extracellular matrix, and heal wounds $[65,66]$. Cigarette smoke exposure may also induce stress-induced senescence, preventing epithelial cell proliferation [Tsuji, unpublished observations]. Thus, cigarette smoke likely augments lung injury not only by inducing epithelial cell death, but also by inhibiting epithelial repair processes. These alterations in the alveolar epithelium following cigarette smoke exposure may contribute to the architectural and functional disruptions that cause the various lung diseases associated with cigarette smoking.

\section{REFERENCES}

1. Church DF, Pryor WA. Free-radical chemistry of cigarette smoke and its toxicological implications. Environ Health Perspect 1985;64:111-126.

2. Pryor WA, Stone K. Oxidants in cigarette smoke. Radicals, hydrogen peroxide, peroxynitrate, and peroxynitrite. Ann NY Acad Sci 1993;686:12-27.

3. Schneeberger EE. Alveolar type I cells. The Lung:Scientific Foundations Second Edition edited by Crystal RG, West JB, Weibel ER, Barnes PJ. Lippincott-Raven, Philadelphia. 1997:535-542.

4. Mason RJ, Shannon JM. Alveolar type II cells. The Lung:Scientific Foundations Second Edition edited by Crystal RG, West JB, Weibel ER, Barnes PJ. Lippincott-Raven, Philadelphia. 1997:543-555.

5. Crapo JD, Barry BE, Gehr P, Bachofen M, Weibel ER. Cell numbers and cell characteristics of the normal human lung. Am Rev Respir Dis 1982;126:332-337.

6. Devereux TR, Serabjit-Singh CJ, Slaughter SR, Wolf CR, Philpot RM, Fouts JR. Identification of cytochrome P-450 isozymes in nonciliated bronchiolar epithelial (Clara) and alveolar type II cells isolated from rabbit lung. Exp Lung Res
1981;2:221-230.

7. Matalon S. Mechanisms and regulation of ion transport in adult mammalian alveolar type II pneumocytes. Am J Physiol 1991;261:C727-C738.

8. Uhal BD. Cell cycle kinetics in the alveolar epithelium. Am J Physiol 1997;272:L1031-1045.

9. Cross CE, van der Vliet A, Eiserich JP, Wong J. Oxidative stress and antioxidants in respiratory tract lining fluids. Oxygen, Gene Expression, and Cellular Function. Lung Biology in Health and Disease edited by Clerch LB, Massaro DJ. Marcel Dekker, New York. 1997:367-398.

10. Nakayama T. Church DF, Pryor WA. Quantitative analysis of the hydrogen peroxide formed in aqueous cigarette tar extracts. Free Radic Biol Med 1989;1:9-15.

11. Stone KK, Bermudez E, Pryor WA. Aqueous extracts of cigarette tar containing the tar free radical cause DNA nicks in mammalian cells. Environ Health Perspect 1994;102:s173-s178.

12. Moreno JJ, Foroozesh M, Church DF, Pryor WA. Release of iron from ferritin by aqueous extracts of cigarette smoke. Chem Res Toxicol 1992;5:116123.

13. Ludwig PW, Hoidal JR. Alterations in leukocyte oxidative metabolism in cigarette smokers. Am Rev Respir Dis 1992;126:977 980.

14. Eiserich JP, van der Vliet A, Handelman GJ, Halliwell B, Cross CE. Dietry antioxidants and cigarette smoke-induced biomolecular damage: a complex interaction. Am J Clin Nutr 1995; 62:s1490-s1500.

15. Rahman I, MacNee W. Oxidant/antioxidant imbalance in smokers and chronic obstructive lung disease. Thorax 1996;51:348-350.

16. Maranzana A, Mehlhorn RJ. Loss of glutathione, ascorbate recycling and free radical scavenging in human erythrocytes exposed to filtered cigarette smoke. Arch Biochem Biophys 1998;350:169-182.

17. Joshi UM, Kodavanti PR, Mehendale HM. Glutathione metabolism and utilization of external thiols by cigarette smoke challenged, isolated rat and rabbit lungs. Toxicol Appl Phamacol 1988; 96:324-335.

18. Rahman I, Li XY, Donaldson K, Harrison DJ, MacNee W. Glutathione homeostasis in alveolar epithelial cells in vitro and lung in vivo under oxidative stress. Am J Physiol 1995;269:L285-L292.

19. Rahman I, MacNee W. Lung glutathione and oxidative stress: implications in cigarette smoke-induced airway disease. Am J Physiol 1999;277:L1067L1088. 
20. Lannan S, Donaldson K, Brown D, MacNee W. Effect of cigarette smoke and its condensates on alveolar epithelial cell injury in vitro. Am J Physiol 1994;266:L92-L100.

21. Morrison D, Rahman I, Lannan S, MacNee W. Epithelial permeability, inflammation, and oxidant stress in the air spaces of smokers. Am J Respir Crit Care Med 1999;159:473-479.

22. York GK, Peirce TH, Schwartz LW, Cross CE. Stimulation by cigarette smoke of glutathione peroxidase system enzyme activities in rat lung. Arch Environ Health 1976;31:286-290.

23. Comhair SA, Erzurum SC. Antioxidant responses to oxidant mediated lung diseases. Am J Physiol 2002;283:L246-L255.

24. Li XY, Rahman I, Donaldson K, MacNee W. Mechanisms of cigarette smoke induced increased airspace permeability. Thorax 1996;51:465-471.

25. Masubuchi T, Koyama S, Sato E, Takamizawa A, Kubo K, Sekiguchi M, Nagai S, Izumi T. Smoke extract stimulates lung epithelial cells to release neutrophil and monocytic chemotactic activity. Am J Pathol 1998;153:1903-1912.

26. Shoji S, Ertl RF, Koyama S, Robbins R, Leikauf G, von Essen S, Rennard SI. Cigarette smoke stimulates release of neutrophil chemotactic activity from cultured bovine bronchial epithelial cells. Clin Sci 1995;88:337-344.

27. Mio T, Romberger DJ, Thompson AB, Robbins RA, Heires A, Rennard SI. Cigarette smoke induces interleukin-8 release from human bronchial epithelial cells. Am J Respir Crit Care Med 1997; 155:1770-1776.

28. Wyatt TA, Heires AJ, Sanderson SD, Floreani AA. Protein kinase $\mathrm{C}$ activation is required for cigarette smoke-enhanced C5a-mediated release of interleukin-8 in human bronchial epithelial cells. Am J Respir Cell Mol Biol 1999;21:283-288.

29. Nakayama T, Kaneco M, Kodama M, Nagata C. Cigarette smoke induces DNA single-strand DNA breaks in human cells. Nature 1985;314:462-464.

30. Howard DJ, Briggs LA, Pritsos CA. Oxidative DNA damage in mouse heart, liver, and lung tissue due to acute side-stream tobacco smoke exposure. Arch Biochem Biophys 1998;352:293-297.

31. Plopper CG, Dungworth DL, Tyler WS. Pulmonary lesions in rats exposed to ozone. A correlated light and electron microscopic study. Am J Pathol 1973;71:375-394.

32. Leanderson P, Tagesson C. Cigarette smokeinduced DNA damage: role of hydroquinone and catechol in the formation of the oxidative DNAadduct, 8-hydroxydeoxyguanosine. Chem Biol Interact 1990;75:71-81.

33. Leanderson P, Tagesson C. Cigarette smokeinduced DNA damage in cultured human lung cells: role of hydroxyl radicals and endonuclease activation. Chem Biol Interact 1992;81:197-208.

34. Kamp DW, Greenberger MJ, Sbalchierro JS, Preusen SE, Weitzman SA. Cigarette smoke augments asbestos-induced alveolar epithelial cell injury.:role of free radicals. Free Radic Biol Med 1998;25:728-739.

35. Jackson JH, Schraufstatter IU, Hyslop PA, Vosbeck K, Sauerheber R, Weitzman SA, Cochrane CG. Role of oxidants in DNA damage. Hydroxyl radical mediates the synergistic DNA damaging effects of asbestos and cigarette smoke. J Clin Invest 1987; 80:1090-1095.

36. Nakajima Y, Aoshiba K, Yasui S, Nagai A. $\mathrm{H}_{2} \mathrm{O}_{2}$ induces apoptosis in bovine tracheal epithelial cells in vitro. Life Sci 1999;64:2489-2496.

37. Cosgrove JP, Borish ET, Church DF, Pryor WA. The metal mediated formation of hydroxyl radical by aqueous extracts of cigarette tar. Biochem Biophys Res Commun 1985;132:390-396.

38. Kamp DW, Srinivasan M, Weitzman SA. Cigarette smoke and asbestos activate poly-ADP-ribose polymerase in alveolar epithelial cells. J Invest Med 2001;49:68-76.

39. Nagai A, Matsumiya H, Hayashi M, Ysui S, Okamoto H, Konno K. Effects of nicotinamide and niacin on bleomycin-induced acute injury and subsequent fibrosis in hamster lungs. Exp Lung Res 1994;20:263-281.

40. Schraufstatter I, Hinshaw DB, Hyslop PA, Spragg RG, Cochrane CG. Oxidant injury of cells. DNA strand-breaks activate polyadenosine diphosphateribose polymerase and lead to depletion of nicotinamide adenosine dinucleotide. J Clin Invest 1986; 77:1312-1320.

41. Spencer JPE, Jenner A, Chimel K, Aruoma OI, Cross CE, Wu R, Halliwell. DNA damage in human respiratory tract epithelial cells: damage by gas phase cigarette smoke apparently involves attack by reactive nitrogen species in addition to oxygen radicals. FEBS Lett 1995;375:179-182.

42. Biadasz L, Massaro DJ. Lung oxidant enzyme gene expression and tolerance to hyperoxia. Oxygen, Gene Expression, and Cellular Function. Lung Biology in Health and Disease ed. by Clerch LB, Massaro DJ. Marcel Dekker, New York. 1997:399-424. 
43. Gilks CB, Price K, Wright JL, Churg A. Antioxidant gene expression in rat lung after exposure to cigarette smoke. Am J Pathol 1998;152:269-278.

44. Rahman I, Smith CAD, Lawson MF, Harrison DJ, MacNee W. Induction of g-glutamylcysteine synthetase by cigarette smoke is associated with AP-1 in human alveolar epithelial cells. FEBS Lett 1996;396:21-25.

45. Jeyapaul J, Jaiswal AK. Nrf2 and c-Jun regulation of antioxidant response element (ARE)-mediated expression and induction of gamma-glutamylcysteine synthetase heavy subunit gene. Biochem Pharmacol 2000;59:1433-1439.

46. Cantin AM, North SL, Hubbard RC, Crystal RG. Normal alveolar epithelial lining fluid contains high levels of glutathione. J Appl Physiol 1987;63:152157.

47. Dinsdale D, Green JA, Manson MM, Lee MJ. The ultrastructural immunolocalization of gammaglutamyltranspeptidase in rat lung: correlation with the histochemical demonstration of enzyme activity. Histochem J 1992;24:144-152.

48. Asayama K, Yokota S, Dobashi K, Kawada Y, Nakane T, Kawaoi A, Nakazawa S. Immunolocalization of cellular glutathione peroxidase in adult rat lungs and quanititative analysis after postembedding immunogold labeling. Histochem Cell Biol 1996;105:383-389.

49. Hoshino Y, Mio T, Nagai S, Miki H, Ito I, Izumi T. Cytotoxic effects of cigarette smoke extracts on an alveolar type II cell derived cell line. Am J Physiol 2001;281:L509-L516.

50. Aoshiba K, Tamaoki J, Nagai A. Acute cigarette smoke exposure induces apoptosis of alveolar macrophages. Am J Physiol 2001;281:L1392-L1401.

51. Hampton MB, Orrenius S. Dual regulation of caspase activity by hydrogen peroxide: implications for apoptosis. FEBS Lett 1997;414:552-556.

52. Nardini M, Finkelstein EI, Reddy S, Valacchi G, Traber M, Cross CE, van der Vliet A. Acroleininduced cytotoxicity in cultured human bronchial epithelial cells. Modulation by alpha tocopherol and ascorbic acid. Toxicology 2002;170:173-185.

53. D’Agostini F, Balansky RM, Izzotti A, Lubet RA, Kelloff GJ, De Flora S. Modulation of apoptosis by cigarette smoke and cancer chemopreventive agents in the respiratory tract of rats. Carcinogenesis 2001;22:375-380.

54. Jung M, Davis WP, Taatjes DJ, Churg A, Mossman BT. Asbestos and cigarette smoke cause increased JR. Effects of cigarette smoke extract on bovine
DNA strand breaks and necrosis in bronchiolar epithelial cells in vivo. Free Radic Biol Med 2000;28:1295-1299.

55. Goldkorn T, Balaban N, Shannon M, Chea V, Matsukuma K, Gilchrist D, Wang H, Chan C. H2O2 acts on cellular membranes to generate ceramide signaling and initiate apoptosis in tracheobronchial epithelial cells. J Cell Sci 1998;111:3209 3220.

56. Chan C, Goldkorn T. Ceramide path in human lung cell death. Am J Respir Cell Mol Biol 2000;22:460468.

57. Larventiadou SN, Chan C, Kawcak T, Ravid T, Tsaba A, van der Vliet A, Rassoly R, Goldkorn T. Ceramide-mediated apoptosis in lung epithelial cells is regulated by glutathione. Am J Respir Cell Mol Biol 2001;25:676-684.

58. Li Y, Zhang W, Mantell LL, Kazzaz JA, Fein AM, Horowitz S. Nuclear factor-kB is activated by hyperoxia but does not protect from cell death. J Cell Biol 1997;272:20646-20649.

59. O'Reilly MA, Staversky RJ, Watkins RH, Maniscalco WM, Keng PC. p53-independent induction of GADD45 and GADD153 in mouse lungs exposed to hyperoxia. Am J Physiol 2000;278:L552-L559.

60. Knight-Lozano CA, Young CG, Burow DL, Hu ZY, Uyeminami D, Pinlerton KE, Ischiropoulos H, Ballinger SW. Cigarette smoke exposure and hypercholesterolemia increase mitochondrial damage in cardiovascular tissues. Circulation 2002;105:849-854.

61. Kasahara Y, Tuder RM, Cool CD, Lynch DA, Flores SC, Voelkel NF. Endothelial cell death and decreased expression of vascular endothelial growth factor and vascular endothelial growth factor receptor 2 in emphysema. Am J Respir Crit Care Med 2001;163:737 744 .

62. Segura-Valdez L, Pardo A, Gaxiola M, Uhal BD, Becerril C, Selman C. Upregulation of gelatinase A and $\mathrm{B}$, collagenase 1 and 2 , and increased parenchymal cell death in COPD. Chest 2000;117:684693.

63. Kasahara Y, Tuder RM, Taraseviciene-Stewart L, Le Cras TD, Abman S, Hirth PK, Waltenberger J, Voelkel NF. Inhibition of VEGF receptors causes lung cell apoptosis and emphysema. J Clin Invest 2000;106:1311-1319.

64. Aoshiba K, Yokohori N, Nagai A. Alveolar wall apoptosis causes lung destruction and emphysematous changes. Am J Respir Mol Cell Biol 2003; 28:555-562.

65. Cantral DE, Sisson JH, Veys T, Rennard SI, Spurzem epithelial cell attachment and migration. Am J 
Physiol 1995;268:L723-L728.

66. Wang H, Liu Xiangde, Umino T, Skold CM, Zhu Y, Kohyama T, Spurzem JR, Romberger DJ, Rennard
SI. Cigarette smoke inhibits human epithelial cell repair processes. Am J Respir Cell Mol Biol 2001; 25:772-779. 